\title{
Comparative study of protozoan communities in full-scale MWTPs in Beijing related to treatment processes
}

\author{
Juan Liu ${ }^{a}$, Min Yang ${ }^{a, *}$, Rong $\mathrm{Qi}^{a}$, Wei $\mathrm{An}^{a}$, Jun Zhou ${ }^{b}$ \\ ${ }^{a}$ State Key Lab of Environmental Aquatic Chemistry, Research Center for Eco-Environmental Sciences, Chinese Academy of Sciences, \\ Beijing 100085, China \\ beijing Drainage Group Co., Ltd., Beijing 100020, China
}

\section{A R T I C L E I N F O}

Article history:

Received 16 August 2007

Received in revised form

16 November 2007

Accepted 18 November 2007

Available online 24 November 2007

Keywords:

Protozoa

Community structure

Municipal wastewater

Treatment process

Cluster analysis

Principal components analysis

\begin{abstract}
A B S T R A C T
The potential influence of process principles and system conditions on shaping protozoan community structures in eight full-scale municipal wastewater treatment systems in Beijing, including four process types, i.e., anaerobic/anoxic/aerobic or anoxic/anaerobic/ aerobic process (A2O), anoxic/aerobic or anaerobic/aerobic process (AO), oxidation ditch (OD) and sequencing batch reactor (SBR), was evaluated with the aid of cluster analysis and principal components analysis (PCA). The species richness and abundance distribution of protozoa varied significantly with the process types: the A2O ecosystems harbored more diverse protozoan communities with higher relative abundance of crawling and sessile ciliates than the other systems. Cluster analysis revealed that the protozoan community structures were in high coordination with the process types, i.e., different systems with the same process principles exhibited similar community structures. The A2O processes displayed a distinctively higher similarity of protozoan community structures than the AO processes, suggesting that the A2O ecosystems were more stable than those of AO. The PCA analyses demonstrated that swimming and carnivorous ciliates were correlated with poor settleability of sludge, and that amoebae were sensitive to DO level. We therefore concluded that protozoan community structures were primarily shaped by treatment process principles, whilst they were also modified by system conditions in terms of operational properties and water quality.
\end{abstract}

(c) 2007 Elsevier Ltd. All rights reserved.

\section{Introduction}

Biological removal of pollutants from sewage is performed by a mixed community of microorganisms in municipal wastewater treatment plants (MWTPs). The success of this biological process is dependant not only on the single role-play of functional bacteria, who are foremost responsible for the biotransformation of waste materials and accordingly has attracted much more special attentions in research fields, but also on the overall "healthy" ecological interactions among the microscopic residents all together (Curds, 1982; Madoni and Ghetti, 1981; Madoni et al., 1993; Martín-Cereceda et al., 1996). In this artificial ecosystem, protozoa serving as primary consumers of bacteria and fungi as well as food sources for metazoa, construct an essential trophic link in food web and therefore make a numerically and functionally significant contribution (Pernthaler et al., 1997; Martín-Cereceda et al., 2001; Degans et al., 2002; Nicolau et al., 2005). In addition to improving the effluent quality through grazing of dispersed bacteria and suspended particles (Curds and Cockburn, 1970;

*Corresponding author. Tel./fax: +861062923475.

E-mail addresses: 54liujuan@163.com (J. Liu), yangmin@rcees.ac.cn (M. Yang), qirong@rcees.ac.cn (R. Qi), anwei@rcees.ac.cn (W. An), zhoujun992@yahoo.com.cn (J. Zhou).

0043-1354/\$ - see front matter (c) 2007 Elsevier Ltd. All rights reserved.

doi:10.1016/j.watres.2007.11.020 


\begin{tabular}{|lll|}
\hline Nomenclature & MLSS mixed liquor suspended solids \\
Symbols and abbreviations & MWTP municipal wastewater treatment plant \\
& & $\mathrm{NH}_{3}-\mathrm{Ne}$ the concentration of ammonia nitrogen in effluent \\
A2O anaerobic/anoxic/aerobic and anoxic/anaerobic/ & $\mathrm{NH}_{3}-\mathrm{Ni}$ the concentration of ammonia nitrogen in influent \\
& $\mathrm{NO}_{3}-\mathrm{N}$ the concentration of nitrates \\
AO aerobic process & $\mathrm{OD}$ & oxidation ditch \\
BODe biological oxygen demand of effluent & $\mathrm{SBR}$ sequencing batch reactor \\
BODi biological oxygen demand of influent & SRT solids residence time \\
DO dissolved oxygen & SVI & sludge volume index \\
HRT hydraulic retention time & & \\
\end{tabular}

Curds, 1982; Salvadó et al., 1995; Lee et al., 2004), protozoa exert potential influence on the treatment system by regulating the morphological and taxonomic structures of bacterial community through top-down predatory behaviors (Šimek et al., 1997; Jürgens et al., 1999; Hahn and Höfle, 1999, 2001). Giving an insight into protozoan communities is hereby of great significance in expanding the holistic understanding of activated-sludge ecosystem, and thus improving the performance of the existing biological treatment processes.

It is accepted that the protozoan communities will be influenced in two pathways: to be manipulated directly by virtue of their inherent sensitivities to environment, and meanwhile to be modified indirectly in accordance with the potential changes of bacterial community structures through food chain (Curds and Cockburn, 1970; Zarda et al., 1998; Jezbera et al., 2005; Nicolau et al., 2005). For building the species-habitat relationship, most previous studies have been devoted to monitoring protozoan communities for predicting effluent quality and plant performance (Curds and Cockburn, 1970; Poole, 1984; Al-Shahwani and Horan, 1991; Salvadó et al., 1995; Martín-Cereceda et al., 1996).The species of protozoa present in activated sludge have been well inventoried as important bio-indicators since last century (Curds and Cockburn, 1970; Madoni and Ghetti, 1981; Madoni et al., 1993; Nicolau et al., 2001). Recently, with the awareness of their potential indications for operating conditions, some researchers have focused on evaluating the association of protozoan species with operational parameters (Esteban et al., 1991; Salvadó and Gracia, 1993; Salvadó, 1994; Martín-Cereceda et al., 1996; Lee et al., 2004). Although the process principle of a treatment system, such as configuration, flow regime as well as aeration mode, etc., also affects the habitat of its microscopic individuals to some extent, its relationship with protozoan communities has been poorly understood.

In this context, systematic analyses on protozoan communities of 8 biological treatment systems in 5 full-scale MWTPs of Beijing were carried out in support of statistical approaches involving multivariate methods, such as cluster analysis and principal components analysis (PCA). These 8 systems include mainly 4 types of process, anaerobic/anoxic/aerobic or anoxic/anaerobic/aerobic process (A2O), anoxic/aerobic or anaerobic/aerobic process (AO), oxidation ditch (OD) and sequencing batch reactor (SBR).

The objectives of this study were to characterize (1) the distribution patterns of protozoan populations in different sewage treatment systems; in order to provide an elucidation on (2) the potential impact of process principles on protozoan communities, i.e. whether the structures of protozoan community vary with different treatment processes, and how; and further to determine (3) the potential contributions of system conditions in terms of operational properties and water quality on characterizing community structures of protozoa.

\section{Materials and methods}

\subsection{Description of wastewater treatment systems investigated}

Five full-scale MWTPs, including eight different treatment systems, in Beijing, China, were investigated. The characteristics of each plant are outlined in Table 1 and the schematic flow diagram of each system is shown in Fig. 1. Plant G, the largest MWTP in China, comprises three complete treatment systems: one anoxic/anaerobic/aerobic process (G1) and two anoxic/aerobic processes (G2 and G3), each of which receives one-third of inflow. Plant $Q$ consists of two parallel treatment systems of $\mathrm{A} 2 \mathrm{O}$ processes, i.e. a modified one (anoxic/anaerobic/aerobic, Q1) and a normal one (anaerobic/ anoxic/aerobic, Q2). These two MWTPs serve as representative in-situ models for comparing the effects of process principles and wastewater sources on protozoan communities. Plant $\mathrm{B}$ with an anaerobic/aerobic process, Plant J (the Pasveer type of OD) and Plant W (SBR) were selected to confirm the potential contributions of process principles on characterizing community structures of protozoa.

\subsection{Sampling protocol}

Samples were collected for three times (October 2005, April 2006 and November 2006). Samples of influent and effluent were collected at the same time, and their characteristics were determined according to standard methods for the examination of water and wastewater (APHA, 1995). The water quality of the influent and effluent during the sampling period was estimated on an average of the three samples and is shown in Table 2. Sludge samples for microscopical examination were collected randomly with 11 plastic bottles from the mixed liquor of the aeration stage immediately prior to solid-liquid separation. For meeting the oxygen demands, it was ensured that only less than two-thirds of the volume of 
Table 1 - Description of eight objecting full-scale municipal wastewater treatment systems in relation to four types of process

\begin{tabular}{lccc}
\hline MWTP & Treatment capacity $\left(\mathrm{m}^{3} / \mathrm{d}\right)$ & Process principle & Sample name \\
\hline Gaobeidian 1 & 250,000 & Anoxic/anaerobic/aerobic & G1-iA2O \\
Gaobeidian 2 & 250,000 & Anoxic/aerobic & G2-AO \\
Gaobeidian 3 & 250,000 & Anoxic/aerobic & G3-AO \\
Qinghe 1 & 100,000 & Anoxic/anaerobic/aerobic & Q1-iA2O \\
Qinghe 2 & 100,000 & Anaerobic/anoxic/aerobic & Q2-A2O \\
Beixiaohe & 40,000 & Anoxic/aerobic & B-AO \\
Jiuxianqiao & 200,000 & Oxidation ditch-Pasveer & J-OD \\
Wujiacun & 80,000 & Sequencing batch reactor & W-SBR \\
\hline
\end{tabular}

each bottle was occupied with the mixed liquor, and that the bottles were lidded untightly. The temperature during sampling was approximately $20^{\circ} \mathrm{C}$.

\subsection{Microscopical examination of protozoa}

All grab samples were completed for microscopic analysis within $5 \mathrm{~h}$ after collection (Madoni and Ghetti, 1981). After shaking, sub-samples of $25 \mu \mathrm{l}$ in volume were extracted with an automatic micropipette for microscopic analysis (Martín-Cereceda et al., 1996). Slides were viewed under an Axioskop 2 epifluorescent microscope (Carl Zeiss, Jena, Germany) mounted with a video camera, using bright-field and differential interference contrast. Direct counting procedures were carried out at magnifications of $\times 100-\times 400$, according to the sizes of species, and were expressed in number of individuals per $\mathrm{ml}$ of mixed liquor. Identification of protozoa was mainly based on morphology and movement (Shen and Zhang, 1990; Patterson, 1996). Whenever necessary, images were taken and documented with the standard software package provided by Zeiss (Axio Vision 4.1). The results for each sample were determined by averaging the counts of three replicates.

\subsection{Statistical analyses}

Since this survey was particularly made with interests in process principles of MWTPs, to minimize any possible confusion resulting from the seasonal changes in temperature and operational malfunctions on occasion, estimation was performed here with averaged data of the three samplings.

In order to reveal the existence of potential correlation between treatment systems and distribution of protozoan populations, multivariate exploratory techniques, which are especially suitable for processing large-sized data containing high dimensionalities and correlations, were carried out with the aid of software STATISTICA for Windows Version 6.0. Prior to conducting statistical analysis, normalization of all measured data was employed with this program to stabilize variance.

Cluster analysis, as one type of multivariate statistics, provide a classification algorithm to link together objects sufficiently similar to each other and then amalgamate successively larger clusters, typically illustrated by the structure of a hierarchical tree with distinct branches (Hansel-Welch et al., 2003; Jiang et al., 2007). Hereby, to characterize the community structures of protozoa with various treatment processes, tree clustering on the amalgamation rule of unweighted pair-group average was conducted. To interpret the relative similarity reflected by linkage distance of neighbors across clusters, correlation coefficients in forms of 1-Pearson $r$ was selected as distance measure in data computing.

On the other hand, to capture the statistical behavior of various treatment system variables, PCA was performed. By way of compiling and classifying these high-dimensional factors simultaneously, PCA was considered appropriate for recovering a vector space of lower dimension and displaying the important information derived from the measured data compacted in a complex data set (Kalin et al., 2001; Yoo et al., 2003; Hansel-Welch et al., 2003; Jiang et al., 2007). Furthermore, to facilitate its visual interpretability, via the correlation matrix of active variables, 2D plots of factor coordinates were produced in this paper.

\section{Results}

\subsection{Species richness and relative abundance of protozoa} in relation to various treatment processes

Data presented here were collected from the eight treatment systems. A total of 67 protozoan morphospecies, attributed to 33 genera were identified, including 48 ciliates, 12 amoebae and 7 flagellates. For data analyses, protozoa were further categorized into eight groups in terms of lifestyles, phenotypic traits and other food preference (Shen and Zhang, 1990; Madoni, 1994; Martín-Cereceda et al., 1996; Lee et al., 2004). Their population distributions in abundance categories were screened on analysis of normal distribution and were listed in Table 3. Changes of protozoan community structures in different treatment systems were depicted in Fig. 2.

Protozoan compositions in terms of species richness and relative abundance in the eight systems rendered generally the same characteristics: first, ciliates >amoebae > flagellates; second, ciliates were overwhelmed by sessile and crawling ones, which have been considered as the key functional components and their dominance usually indicated the high 
a) Gaobeidian 1

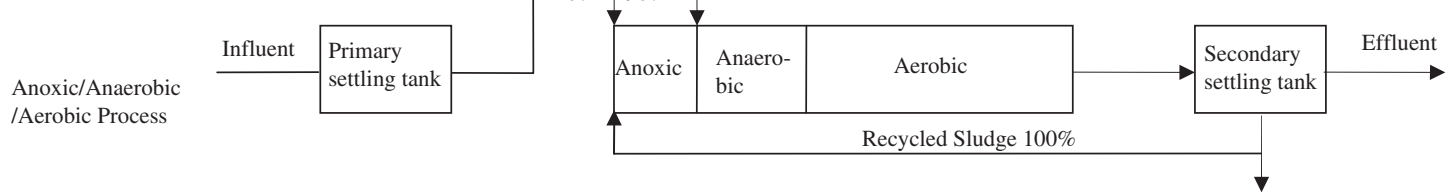

b) Gaobeidian 2

Anoxic/Aerobic Process

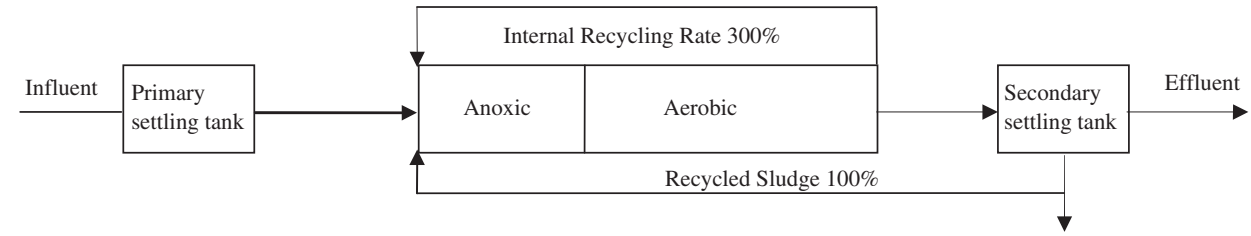

c) Gaobeidian 3

Anoxic/Aerobic Process

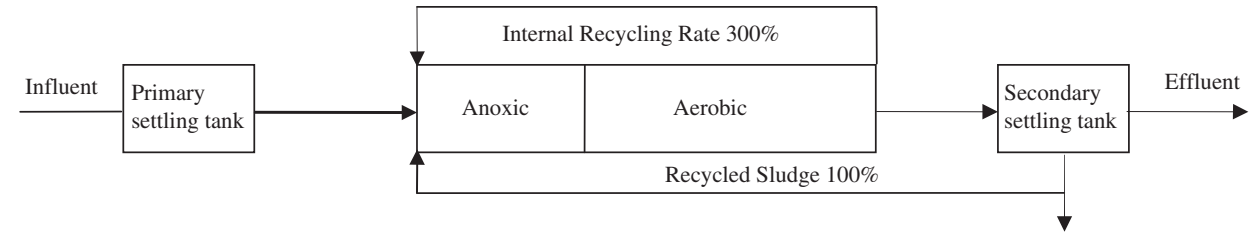

d) Qinghe 1

Anoxic/Anaerobic /Aerobic Process

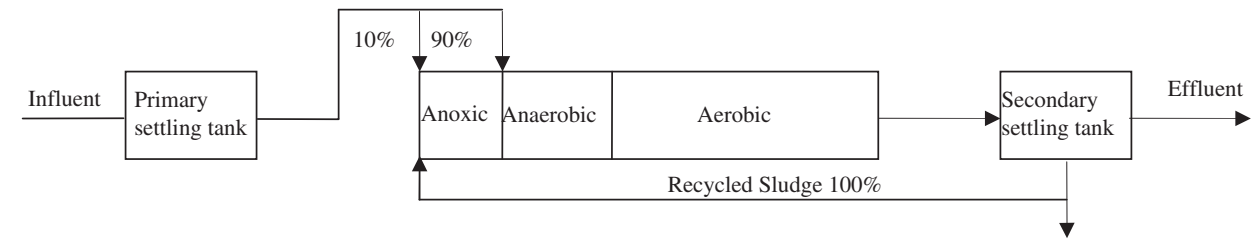

e) Qinghe 2
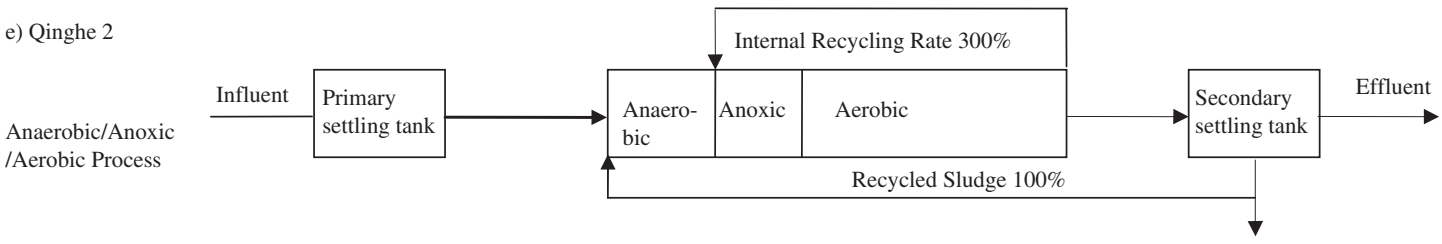

f) Jiuxianqiao

Oxidation Ditch

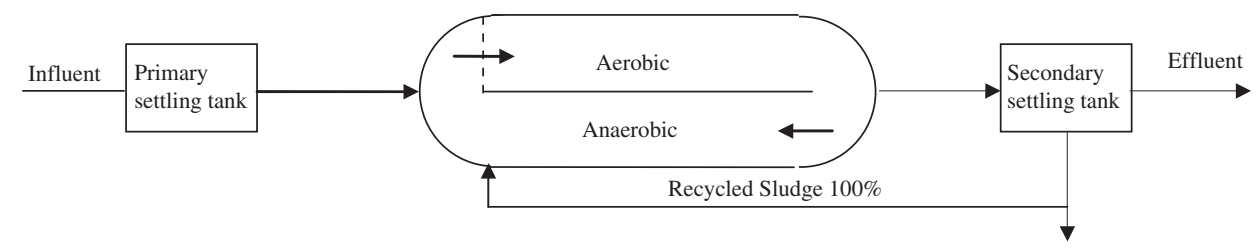

g) Beixiaohe

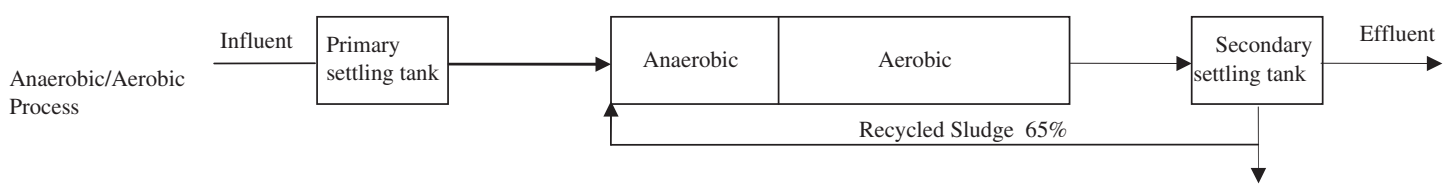

h) Wujiacun

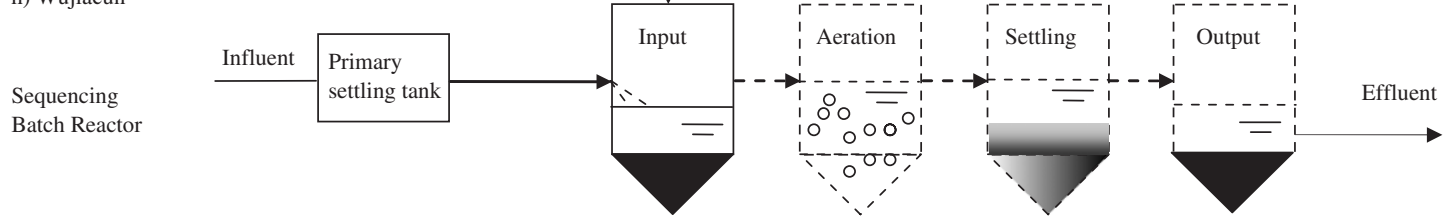

Fig. 1 - Flow charts of eight full-scale municipal wastewater treatment systems investigated in this study. 
Table 2 - Physico-chemical and operational characteristics of eight full-scale municipal wastewater treatment systems investigated in this study

\begin{tabular}{|c|c|c|c|c|c|c|c|c|c|c|}
\hline \multirow[t]{2}{*}{ Plants } & \multicolumn{2}{|c|}{ Influent } & \multicolumn{5}{|c|}{ Aeration tank } & \multicolumn{3}{|c|}{ Effluent } \\
\hline & $\begin{array}{l}\text { BOD } \\
(\mathrm{mg} / \mathrm{l})\end{array}$ & $\begin{array}{c}\mathrm{NH}_{3}-\mathrm{N} \\
(\mathrm{mg} / \mathrm{l})\end{array}$ & $\begin{array}{l}\text { MLSS } \\
(\mathrm{mg} / \mathrm{l})\end{array}$ & $\begin{array}{c}\text { SVI } \\
(\mathrm{ml} / \mathrm{g})\end{array}$ & $\begin{array}{l}\text { HRT } \\
\text { (h) }\end{array}$ & $\begin{array}{l}\text { SRT } \\
\text { (d) }\end{array}$ & $\begin{array}{c}\mathrm{DO} \\
(\mathrm{mg} / \mathrm{l})\end{array}$ & $\begin{array}{l}\text { BOD } \\
(\mathrm{mg} / \mathrm{l})\end{array}$ & $\begin{array}{c}\mathrm{NH}-\mathrm{N}_{3} \\
(\mathrm{mg} / \mathrm{l})\end{array}$ & $\begin{array}{c}\mathrm{NO}_{3}-\mathrm{N} \\
(\mathrm{mg} / \mathrm{l})\end{array}$ \\
\hline Gaobeidian 1 & $204 \pm 52$ & $21.1 \pm 6.3$ & $1540 \pm 273$ & $152 \pm 32$ & 7.2 & 15 & $1.20 \pm 0.1$ & $11.3 \pm 4.7$ & $8.0 \pm 5.1$ & $13.5 \pm 8.3$ \\
\hline Gaobeidian 2 & $215 \pm 58$ & $25.8 \pm 8.1$ & $2533 \pm 523$ & $130 \pm 66$ & 7.0 & 15 & $2.00 \pm 0.3$ & $10.9 \pm 5.4$ & $13.3 \pm 10.4$ & $12.6 \pm 11.1$ \\
\hline Gaobeidian 3 & $194 \pm 47$ & $23.1 \pm 6.9$ & $2318 \pm 477$ & $146 \pm 59$ & 7.0 & 15 & $1.70 \pm 0.3$ & $12.5 \pm 3.1$ & $8.5 \pm 7.9$ & $9.6 \pm 9.1$ \\
\hline Qinghe 1 & $170 \pm 37$ & $45.2 \pm 8.5$ & $1841 \pm 203$ & $71 \pm 27$ & 9.6 & 6 & $1.20 \pm 0.3$ & $11.0 \pm 8.6$ & $2.6 \pm 2.1$ & $21.4 \pm 8.5$ \\
\hline Qinghe 2 & $158 \pm 34$ & $40.7 \pm 7.5$ & $1805 \pm 211$ & $76 \pm 22$ & 10.8 & 6 & $1.50 \pm 0.4$ & $11.2 \pm 7.5$ & $2.3 \pm 1.9$ & $19.6 \pm 7.6$ \\
\hline Beixiaohe & $211 \pm 67$ & $42.1 \pm 12.7$ & $1039 \pm 263$ & $197 \pm 153$ & 8.0 & 10 & $1.20 \pm 0.1$ & $10.5 \pm 8.1$ & $25.7 \pm 15.6$ & $6.6 \pm 4.1$ \\
\hline Jiuxianqiao & $223 \pm 71$ & $46.9 \pm 7.5$ & $4041 \pm 473$ & $56 \pm 27$ & 15.7 & 16 & $2.00 \pm 0.3$ & $10.3 \pm 7.1$ & $2.8 \pm 1.7$ & $5.2 \pm 2.7$ \\
\hline Wujiacun & $151 \pm 47$ & $45.0 \pm 6.7$ & $4520 \pm 513$ & $62 \pm 44$ & 4.0 & 15 & $1.60 \pm 0.2$ & $9.4 \pm 4.1$ & $16.0 \pm 12.1$ & $13.0 \pm 8.1$ \\
\hline
\end{tabular}

efficiency of an activated-sludge system (Madoni, 1994). As compared with each other, however, protozoan distribution varied in correspondence with treatment processes. The A2O ecosystems of Plant G1, Q1 and Q2, harbored the most diverse protozoan communities in a range of species numbers from 41 up to 50. Whilst, all AO systems including Plant B, G3 as well as G2 exhibited relatively lower numbers of species (approximately 40), followed by OD (34) and SBR (below 30).

Accompanied by varying characteristics of taxonomic compositions, relative abundance appeared a pronounced distinction with regard to different processes. Along with its preponderance in numerous taxa, the three A2O systems represented the most extraordinary proportions of sessile and crawling ciliates, suggesting that the $\mathrm{A} 2 \mathrm{O}$ process might be more stable and efficient in comparison with the other processes studied in this survey (Madoni, 1994). It is noteworthy that although virtually poor species richness was encountered in SBR, the relative abundance of sessile and crawling ciliates in this process reached the level equivalent to A2O. It is interesting that testae and naked amoebae, whose indicative significance in activated sludge ecosystems are still not so clear, were relatively abundant in the OD process. For the AO systems, testae and naked amoebae as well as carnivorous ciliates appeared relatively diverse and abundant. Carnivorous ciliates are believed to function indicatively as deficient sedimentation of the sludge (MartínCereceda et al., 1996; Lee et al., 2004). It is noted that Plant B (B-AO) had a markedly higher relative abundance of carnivorous ciliates, which is in correspondence to its relatively bad sludge settleability (average SVI, $197 \mathrm{ml} \mathrm{g}^{-1}$ ).

\subsection{Association of protozoan community structures with process principles}

For further comparison of the entire protozoan community structures among different processes, a more systemic algorithm of tree clustering was adopted, depending on both taxonomic and numerical distributions of protozoa in the eight treatment systems, and a horizontal dendrogram derived from this multivariate analysis was constructed in Fig. 3.

Four major clusters of protozoan communities were in coordination with the four major types of treatment process. The nearest neighbors of Plants Q1, Q2 and G1 with the same process formed the A2O cluster, which declared a much higher similarity than the other clusters. Successively larger clusters aggregated by process OD and then adjacent SBR indicated a relative similarity of these two processes to A2O. Meanwhile, away from them, the furthest grouping of process $\mathrm{AO}$, which demonstrated a marked distinction from the uppers, comprised a sub-group of anoxic/aerobic process in Plants G2 and G3, and an anaerobic/aerobic process in Plant B in addition. The long distance within this AO cluster denoted a relatively low similarity to one another. On all account, the emerging clusters apparently formed in process order: Group A2O-OD-SBR-Group AO, which clearly mirrored a strong ecotype-habitat relationship. That is, ecosystems with respect to the same process principles were colonized by populations of the most similar structures.

However, even in the $\mathrm{A} 2 \mathrm{O}$ process group, the three systems of G1-A2O, Q1-A2O and Q2-A2O, still presented some differences from each other in terms of protozoan community structures. Q1-A2O and Q2-A2O are two parallel systems in Plant $Q$, and their main difference is in the sequence of anaerobic and anoxic units (Fig. 1). The difference between G1-A2O and Q1-A2O is mainly in their wastewater sources and operating conditions. The higher similarity between Q1-A2O and Q2-A2O systems suggested that, besides the process principle, the source of raw wastewater and the operating conditions of a treatment system might be another two important factors determining the similarity of protozoan community structures. It also seemed that the sequence of anaerobic and anoxic units in A2O systems have less significant effect on community structures.

The overall state of a treatment system can be defined mainly by two parts, namely process principles and system conditions in terms of operational properties and water quality. These two definitive features exert their potential influence together on characterizing protozoan communities 
Table 3 - Population distributions of protozoa expressed in abundance categories

\begin{tabular}{|c|c|c|c|c|c|c|c|c|c|}
\hline Functional groups & Species & G1-iA2O & $\mathrm{G} 2-\mathrm{AO}$ & G3-AO & Q1-iA2O & Q2-A2O & $\mathrm{B}-\mathrm{AO}$ & $\mathrm{J}-\mathrm{OD}$ & W-SBR \\
\hline \multirow[t]{3}{*}{ Swimming ciliates } & Colpoda sp. & - & + & ++ & - & - & ++ & - & - \\
\hline & Loxophyllum uninucleatum & + & - & - & - & + & - & - & - \\
\hline & Paramecium caudatum & - & + & + & - & - & + & - & - \\
\hline \multirow[t]{9}{*}{ Crawling ciliates } & Aspidisca costata & ++++ & - & - & ++ & +++ & - & +++ & ++ \\
\hline & Aspidisca lynceus & +++ & ++ & ++ & ++ & ++ & ++ & ++ & ++ \\
\hline & Aspidisca sulcata & +++ & ++ & ++ & + & + & +++ & ++ & ++ \\
\hline & Chilodonella aplanata & + & - & ++ & + & + & ++ & ++ & - \\
\hline & Chilodonella capucina & - & - & - & - & - & - & ++ & - \\
\hline & Chilodonella uncinata & + & ++ & ++ & + & + & ++ & +++ & ++ \\
\hline & Euplotes affinis & + & ++ & ++ & + & + & + & +++ & - \\
\hline & Euplotes muscicola & - & - & - & + & + & - & - & - \\
\hline & Euplotes patella & + & - & - & - & - & - & - & - \\
\hline \multirow[t]{22}{*}{ Sessile ciliates } & Carchesium polypinum & ++ & - & - & ++ & ++ & - & +++ & ++ \\
\hline & Epistylis lascustris & +++ & +++ & +++ & ++++ & +++ & +++ & +++ & +++ \\
\hline & Epistylis plicatilis & ++++ & + & +++ & ++++ & ++++ & +++ & +++ & +++ \\
\hline & Epistylis sp. & ++ & + & ++ & + & ++ & + & + & ++ \\
\hline & Epistylis urceolata & +++ & +++ & ++++ & +++ & +++ & +++ & +++ & +++ \\
\hline & Haplocaulus sp. & ++ & - & - & - & - & - & + & - \\
\hline & Opercularia cylindrata & + & + & ++ & + & ++ & + & - & + \\
\hline & Opercularia microdiscum & + & + & + & + & ++ & +++ & - & + \\
\hline & Opercularia phryganeae & + & + & ++ & + & ++ & ++ & ++ & + \\
\hline & Pseudovorticella moninata & - & - & - & - & + & - & - & - \\
\hline & Vorticella aequilata & + & - & - & ++ & ++ & - & ++ & - \\
\hline & Vorticella campanula & ++ & - & - & + & ++ & - & - & - \\
\hline & Vorticella convallaria & +++ & + & ++ & ++ & ++ & + & + & +++ \\
\hline & Vorticella cupifera & + & - & - & + & + & - & - & - \\
\hline & Vorticella elongata & + & - & - & + & + & - & - & - \\
\hline & Vorticella fromenteli & + & - & - & + & ++ & - & - & - \\
\hline & Vorticella hamata & ++ & ++ & ++ & ++ & ++ & + & - & + \\
\hline & Vorticella microstoma & + & ++ & + & + & + & + & ++ & + \\
\hline & Vorticella octava & + & + & + & + & ++ & +++ & + & + \\
\hline & Vorticella picta & ++ & - & - & + & ++ & - & - & - \\
\hline & Vorticella putrina & ++ & +++ & + & + & ++ & + & - & - \\
\hline & Vorticella striata & + & + & ++ & + & + & + & ++ & ++ \\
\hline
\end{tabular}




\begin{tabular}{|c|c|c|c|c|c|c|c|c|c|}
\hline \multirow[t]{14}{*}{ Carnivorous ciliates } & Acineta tuberosa & + & + & + & + & + & + & - & - \\
\hline & Coleps hirtus & + & + & + & + & + & + & +++ & + \\
\hline & Coleps elongatus & + & + & + & + & + & + & - & - \\
\hline & Hemiophrys agilis & - & - & + & - & - & ++ & - & +++ \\
\hline & Hemiophrys pectinata & - & - & - & - & + & - & - & - \\
\hline & Hemiophrys pleurosigma & - & - & +++ & - & - & - & - & - \\
\hline & Hemiophrys punctata & - & + & + & - & - & + & - & ++ \\
\hline & Litonotus carinatus & +++ & ++ & ++ & + & + & +++ & - & - \\
\hline & Litonotus fasciola & - & - & - & - & + & - & - & - \\
\hline & Litonotus lamella & + & ++ & ++ & - & - & ++ & - & - \\
\hline & Litonotus obtusus & - & - & - & + & + & - & - & - \\
\hline & Podophrya fixa & + & - & - & - & - & - & - & - \\
\hline & Tokophrya quadripatite & + & - & + & + & + & + & + & + \\
\hline & Trachelophyllum pusillum & +++ & - & ++ & ++ & + & +++ & - & - \\
\hline \multirow[t]{7}{*}{ Naked amoebae } & Cashia limacoides & - & + & + & - & - & + & - & - \\
\hline & $\begin{array}{l}\text { Hartmanella } \\
\text { cantabrigiensis }\end{array}$ & - & - & + & - & - & - & ++ & - \\
\hline & Mayorella cypressa & - & + & + & - & - & + & - & - \\
\hline & Mayorella hohuensis & + & + & + & + & - & + & ++ & - \\
\hline & Saccamoeba gongornia & - & + & + & - & - & + & + & - \\
\hline & Striamoeba striata & + & + & + & + & + & + & ++ & - \\
\hline & $\begin{array}{l}\text { Thecamoeba } \\
\text { sphaeronucleolus }\end{array}$ & + & + & + & - & + & + & + & - \\
\hline \multirow[t]{5}{*}{ Testae amoebae } & $\begin{array}{l}\text { Arcella gibbosa } \\
\text { mitriformis }\end{array}$ & + & + & - & - & - & - & + & - \\
\hline & Arcella hemisphaerica & + & ++ & ++ & + & ++ & + & ++ & + \\
\hline & Arcella nulgaris & + & ++ & + & + & ++ & + & ++ & + \\
\hline & Arcella catinus & + & + & + & - & + & + & + & - \\
\hline & Euglypha tuberculata & - & + & - & - & - & + & + & - \\
\hline \multirow{3}{*}{$\begin{array}{l}\text { Heterotrophic } \\
\text { flagellates }\end{array}$} & Bodo sp. & + & + & - & + & + & + & + & + \\
\hline & Peranema sp. & + & - & - & - & - & - & - & + \\
\hline & Peranema trichophorum & + & + & - & - & - & - & + & + \\
\hline \multirow{4}{*}{$\begin{array}{l}\text { Autotrophic } \\
\text { flagellates }\end{array}$} & Anisonema acinus & + & - & - & - & + & - & + & - \\
\hline & Entosiphon sulcatum & + & + & + & + & + & + & - & - \\
\hline & Oikomonas socialis & + & + & + & - & - & ++ & - & - \\
\hline & Polyoeca dumosa & - & - & - & + & + & - & - & - \\
\hline
\end{tabular}



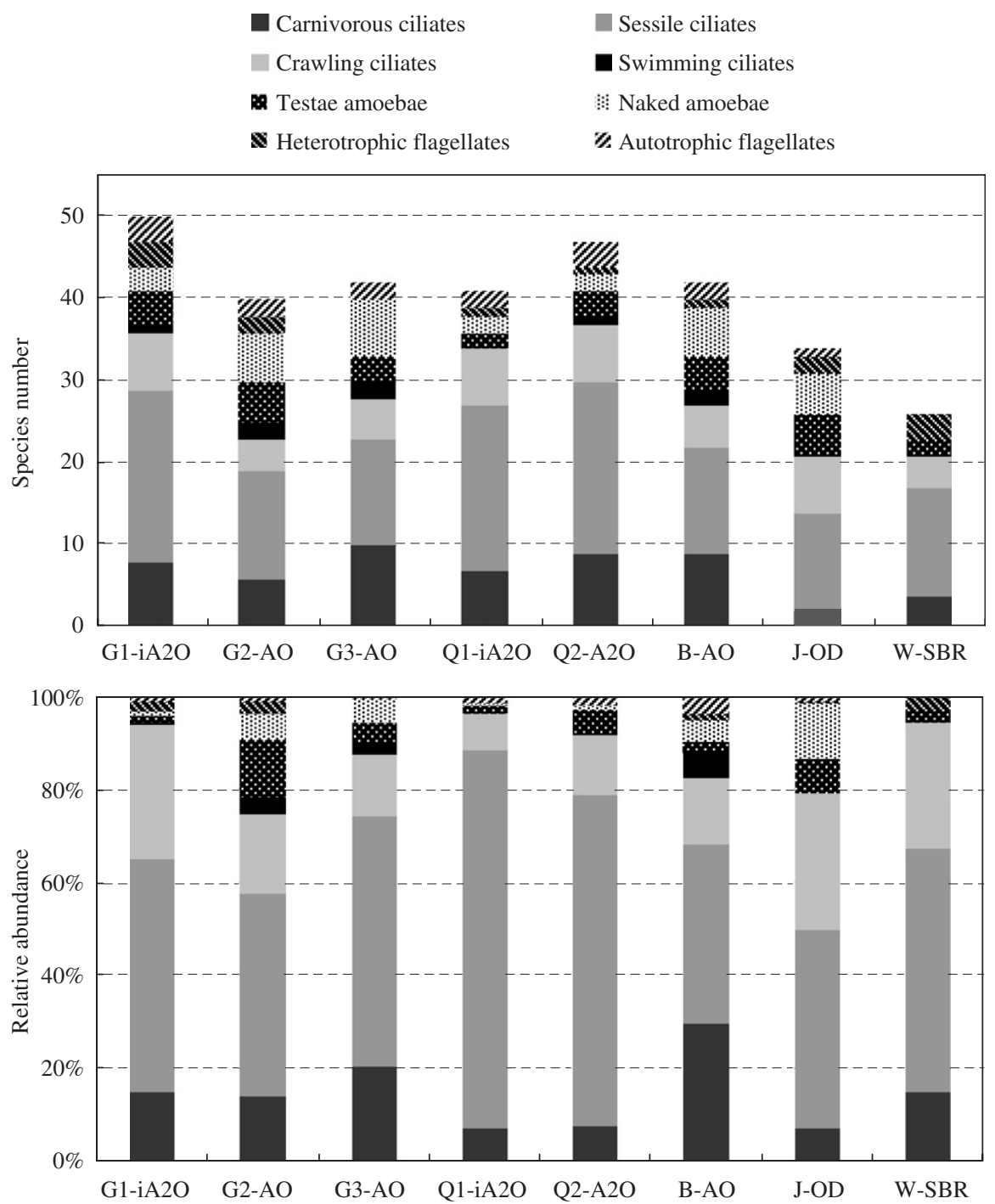

Fig. 2 - Species richness and abundance distribution of protozoa in functional groups.

in a treatment system. It is therefore also essential to know how protozoan community structures are affected by system conditions.

\subsection{Association of protozoan community structures with operational properties and water quality}

To understand the effects of system conditions in terms of operational properties and water quality, two PCA analyses with extracted principal components subjected to Varimax Rotation were designed representatively. Loading biplots of PCA with protozoan communities imposed on were performed to detect how these variables interacted to modify protozoan communities. In these analyses, DO was used both as an operational and water quality variables.

Table 4 showed the PCA of operational properties and protozoan communities. The first two factors with eigenvalues of 2.45 and 1.45 , respectively, captured nearly $78 \%$ of the accumulated variance and were selected as a pair of effective axes to generate a bidimensional vector space. The PCA biplot with a correlation circle was illustrated in Fig. 4. Two welldefined groups were acquired on the basis of regions occupied by variables, i.e. the closer the pattern the stronger the interrelation. MLSS, DO and two kinds of amoebae formed one group. The close correlation between MLSS and DO was also reported in previous research (Yoo et al., 2003). Statistically significant variables derived from the PCA analyses were further quantitatively correlated in Pearson coefficients with populations of protozoa in the eight systems, as shown in Table 5. It also revealed that DO was correlated markedly with amoebae (Pearson $=0.86, P<0.05$ ), which indicated that amoebae were especially sensitive to DO level in activated sludge systems. In the other group, the close relationship between SVI and carnivorous and swimming ciliates reiterated that these ciliates might have affected sludge settleability significantly as discussed above. SVI showed a close positive correlation to carnivorous and swimming ciliates with relatively higher values of 0.92 and 0.86 , respectively $(P<0.05)$ (see Table 5 ). Our results are in good agreement with previous studies, in which these functional ciliates such as Litonous lamella and 


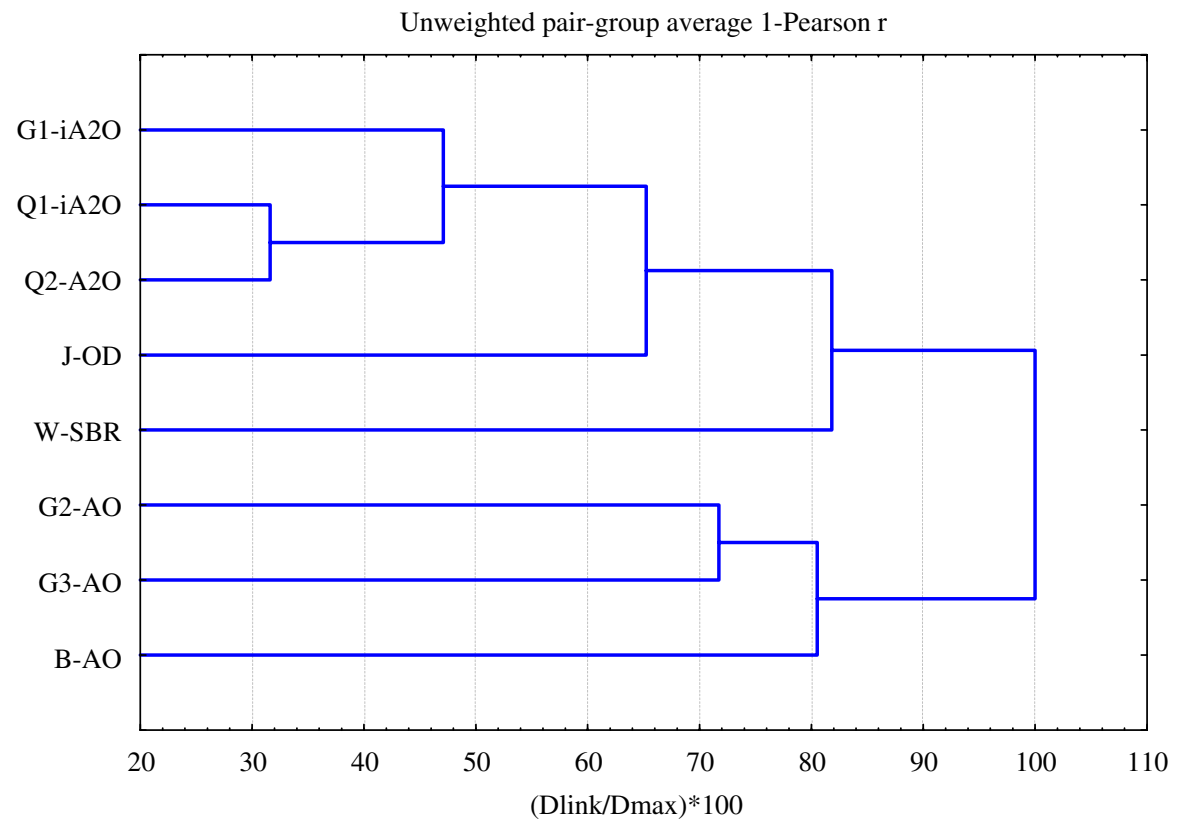

Fig. 3 - Dendrogram of protozoan communities in relation to various treatment processes.

Table 4 - Contributions of operational and protozoan variables derived from PCA with 5 PCs

\begin{tabular}{lccccc}
\hline & Factor 1 & Factor 2 & Factor 3 & Factor 4 & Factor 5 \\
\hline Eigenvalue & 2.45 & 1.45 & 0.78 & 0.27 & 0.05 \\
Cumulative eigenvalue & 2.45 & 3.90 & 4.68 & 5.95 & 5.00 \\
\% Total variance & 48.99 & 28.94 & 15.72 & 9.35 & 1.00 \\
Cumulative variance \% & 48.99 & 77.93 & 93.65 & & \\
\hline
\end{tabular}

Amphileptus sp. were observed in activated sludge with poor settleability (Martín-Cereceda et al., 1996; Lee et al., 2004).

Another PCA analysis on the association between water quality and protozoan communities was interpreted in Table 6. The first two PCs were significant with a cumulative variance of more than $64 \%$ and respective eigenvalue of 2.13 and 1.73. The ordination of this bidimensional space was plotted in Fig. 5. $\mathrm{NO}_{3}^{-}-\mathrm{N}$ and sessile ciliates could be grouped together, suggesting that sessile ciliates might be related with nitrifiers to some extent. However, the correlation significance that resulted from Pearson correlation analysis was relatively low (data not shown). This predator-prey interaction in relation to nitrification is continued in our lab. It is interesting that $\mathrm{DO}, \mathrm{NH}_{3}-\mathrm{Ne}$ and $\mathrm{BODi}$ were clumped together with most protozoan communities into a large speciesquality cluster. Similar relationship between DO and amoebae was also observed in Fig. 4, which depicted the inter-relation between operational and protozoan community variables. A positive correlation of $0.73(P<0.05)$ between $\mathrm{NH}_{3}-\mathrm{Ne}$ and carnivorous ciliates (see Table 5 ) corroborated that carnivorous ciliates were related not only with SVI but also with $\mathrm{NH}_{3}-\mathrm{Ne}$. The reason, however, requires further research.

The above PCA and Pearson analyses results demonstrated that while protozoan community structures were determined by the process principles to a large extent, they were also modified by system conditions in respect of operational properties and water quality.

\section{Discussion}

\subsection{Changes of community structures with various processes}

While the microbial community structures of activated sludge have some general characteristics in common, it is reasonable to propose that pronounced differences do exist in various treatment systems (Madoni and Ghetti, 1981; Forney et al., 2001). The assumption that protozoan ecotype was somewhat associated with process principles, in terms of different configurations or regimes, was confirmed by the above results. The taxonomic composition and population distribution of protozoa appeared to vary greatly with types of treatment processes. The ecologically significant groups of crawling and sessile ciliates were noted as an extraordinary diversity and abundance in the $\mathrm{A} 2 \mathrm{O}$ systems.

To date, the underlying reason that treatment processes specifically drive the pattern of protozoan distributions in this way is not well known. Further studies aiming for explaining this are conducted in details by our group. 
Necessarily speaking, besides the ciliates, who act certainly as the predominant inhabitants in the activated sludge and thus were studied preferably by researchers, testae amoebae were observed with relatively higher frequencies and sometimes with considerable abundance in this study. Although these amoebae have been assumed to be

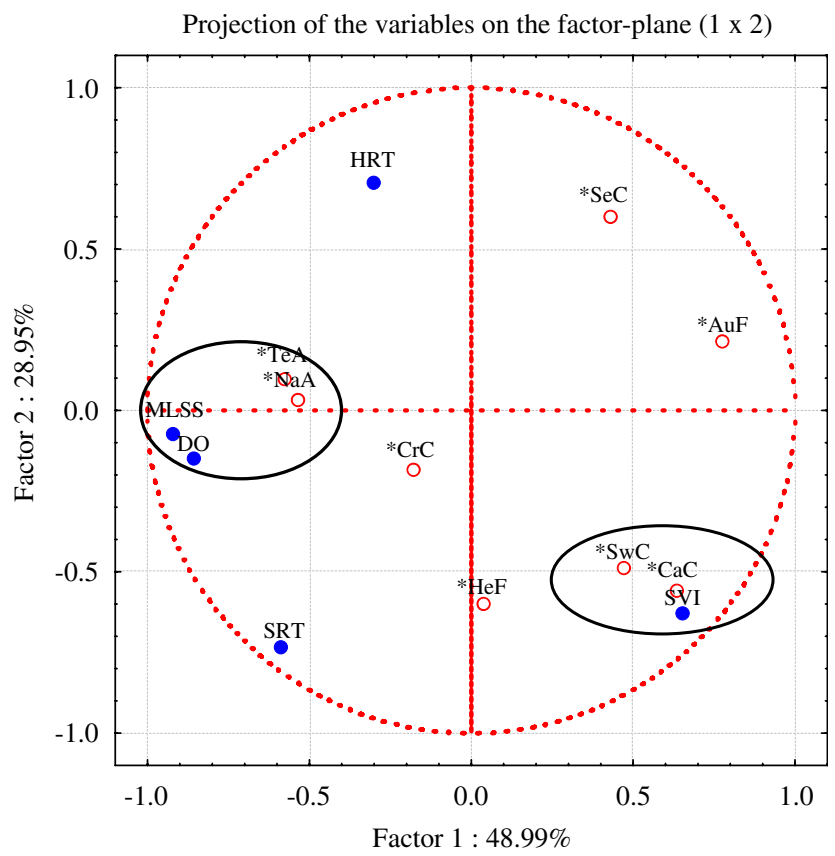

Fig. 4 - PCA analysis of operational characteristics and protozoan populations. Protozoan variables were labeled as follows: carnivorous ciliates, CaC; sessile ciliates, SeC; crawling ciliates, CrC; swimming ciliates, SwC; testae amoebae, TeA; naked amoebae, NaA; heterotrophic flagellates, HeF; autotrophic flagellates, AuF. important in terms of their equivalent body sizes and appetites for bacterial populations to ciliates, there still remain scarce data in related studies (Shen and Zhang, 1990; Foissner, 1999). Upon that, we pose a challenging notion of more extensive studies emphasized on their ecological significance.

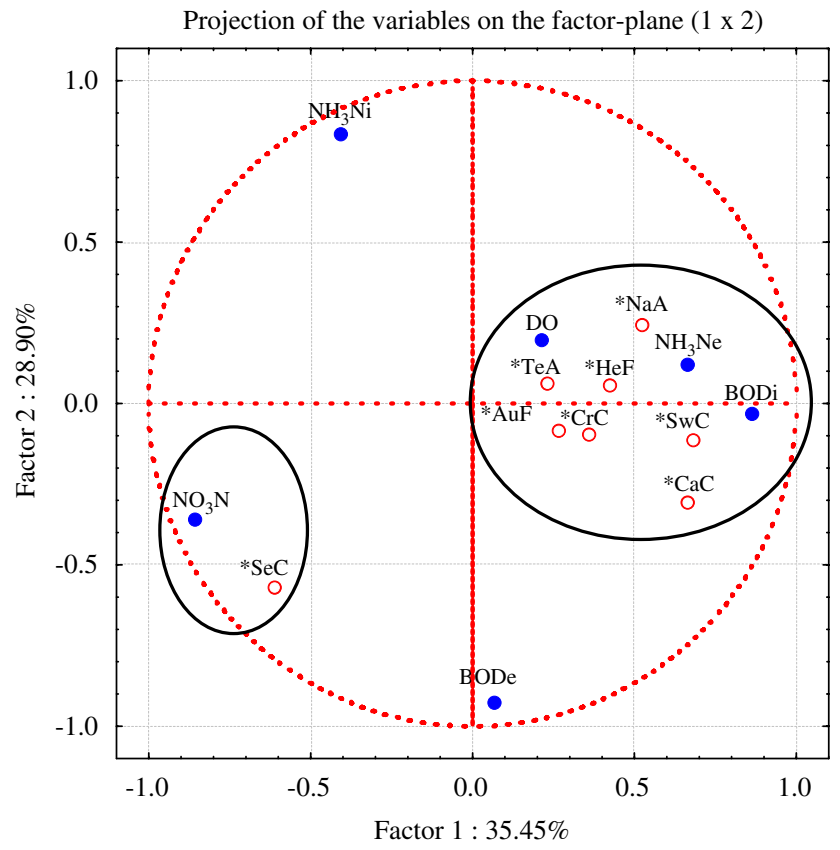

Fig. 5 - PCA analysis of water quality and protozoan populations. Protozoan variables were labeled as follows: carnivorous ciliates, CaC; sessile ciliates, SeC; crawling ciliates, CrC; swimming ciliates, SwC; testae amoebae, TeA; naked amoebae, NaA; heterotrophic flagellates, HeF; autotrophic flagellates, AuF.

Table 5 - Correlation coefficients between protozoa and significant treatment variables derived from PCA

\begin{tabular}{|c|c|c|c|c|c|c|c|c|}
\hline & $\begin{array}{l}\text { Carnivorous } \\
\text { ciliates }\end{array}$ & $\begin{array}{l}\text { Sessile } \\
\text { ciliates }\end{array}$ & $\begin{array}{l}\text { Crawling } \\
\text { ciliates }\end{array}$ & $\begin{array}{l}\text { Swimming } \\
\text { ciliates }\end{array}$ & $\begin{array}{c}\text { Testae } \\
\text { amoebae }\end{array}$ & $\begin{array}{c}\text { Naked } \\
\text { amoebae }\end{array}$ & $\begin{array}{l}\text { Heterotrophic } \\
\text { flagellates }\end{array}$ & $\begin{array}{l}\text { Autotrophic } \\
\text { flagellates }\end{array}$ \\
\hline SVI & $0.92^{*}$ & -0.21 & 0.06 & $0.86^{*}$ & -0.19 & -0.02 & 0.30 & 0.59 \\
\hline DO & -0.46 & -0.54 & -0.03 & -0.08 & $0.86^{*}$ & 0.61 & -0.11 & -0.62 \\
\hline $\begin{array}{l}\mathrm{NH}_{3}- \\
\mathrm{Ne}\end{array}$ & $0.73^{*}$ & -0.53 & 0.16 & 0.61 & -0.39 & -0.20 & 0.68 & 0.35 \\
\hline
\end{tabular}

Table 6 - Contributions of water quality and protozoan variables derived from PCA with 6 PCs

\begin{tabular}{|c|c|c|c|c|c|c|}
\hline & Factor 1 & Factor 2 & Factor 3 & Factor 4 & Factor 5 & Factor 6 \\
\hline Eigenvalue & 2.13 & 1.73 & 1.39 & 0.45 & 0.26 & 0.04 \\
\hline Cumulative eigenvalue & 2.13 & 3.86 & 5.25 & 5.70 & 5.96 & 6.00 \\
\hline$\%$ Total variance & 35.45 & 28.90 & 23.12 & 7.45 & 4.31 & 0.77 \\
\hline Cumulative variance \% & 35.45 & 64.35 & 87.47 & 94.92 & 99.23 & 100 \\
\hline
\end{tabular}




\subsection{Community stability in relation to different process principles}

From cluster interpretation, the community structures of protozoa emerged clearly in a very high coordination with process principles rather than influent sources or operating conditions. However, the difference between Group A2O and Group AO in terms of the similarity within each group revealed that the $\mathrm{A} 2 \mathrm{O}$ process have a much higher stable protozoan communities in comparison with AO.

As shown in Fig. 3, the A2O process marked a distinctively higher similarity of protozoan community structures among different treatment systems. In contrast, AO (anoxic/aerobic) process displayed another sub-cluster with much lower similarity of structures even in the parallel trains of Plant G working under almost identical conditions. Accordingly, a higher ecotype stability of process A2O could be concluded. And as a higher level in food chain, this stable structure of protozoa might be considered informative of the structural stability of bacterial communities and thus functional stability of the overall ecosystem.

To assess the functional aspects of a community, both species richness and community structures should be integrated (Dighton, 1997). The underlying reasons that A2O ecosystem appears to be more stable could be therefore given in such two pathways. The highest species richness as descried above was considered as one of the most important properties for A2O to resist disturbance. That is, the higher degree of redundancy in species, the generally higher degree of stability in biological functions (Griffiths et al., 2000, 2001). The relatively higher species richness of the $\mathrm{A} 2 \mathrm{O}$ process (see Fig. 2) is related with its more complicated configuration: there exist three different environments, i.e., anaerobic, anoxic and aerobic, in the treatment system. Compared with $\mathrm{AO}$ (anoxic/aerobic), the A2O process has an additional anaerobic unit to improve the biodegradability of wastewater by fermentation and to accomplish biological phosphorus removal. There thus occurred a much richer composition of bacteria, especially phosphate accumulation organisms, as well as richer actinomycotic and yeast populations (Liu et al., 2007). As an ecologically trophic link with bacteria, a predatory diverse and complex community of protozoa was born out accordingly. In addition to species richness, characteristics of community structures are also responsible for the high stability of A2O. As mentioned above, A2O was typically colonized by the most predominant populations of attached and crawling ciliates, which preferred to dwell in the flocs and was therefore testified by Madoni (1994) to maintain dynamic stability in an efficient activated-sludge ecosystem. These results were also corroborated by other observations that the attached and crawling ciliates were the most representative groups in a stable aeration tank (MartínCereceda et al., 1996; Salvadó et al., 1995).

It is noteworthy that the AO process exhibited fairly lessstable community structures and was thus unsuccessful to maintain treatment performance, which was also reflected in the factual operating practice of Plants G2 and G3. Even then, it is unlikely to conclude that the A2O ecosystem somewhat displays a certain competence for decomposition or degradation with higher efficiency than the others.

\section{Conclusions}

I. The protozoan community structures were primarily determined by treatment process principles, whilst they were also modified by system conditions in terms of operational properties and water quality.

II. The A2O ecosystems exhibited higher similarity and diversity of protozoan community structures with higher relative abundance of crawling and sessile ciliates than the other systems investigated. Cluster analysis revealed that the $\mathrm{A} 2 \mathrm{O}$ ecosystems were more stable than those of AO.

III. PCA demonstrated that: (1) swimming and carnivorous ciliates were correlated with poor settleability of sludge; (2) amoebae were sensitive to DO level; and (3) sessile ciliates were associated with nitrifiers to some extent.

\section{Acknowledgements}

This study was financially supported by the international cooperation project of the National Natural Science Foundation of China (no. 20521140076, 50525824) and by the Ministry of Science and Technology, China (2006DFA91870). We are grateful to Beijing Drainage Group Co., Ltd. for sampling assistance.

\section{Appendix A. Supplementary materials}

Supplementary data associated with this article can be found in the online version at doi:10.1016/j.watres.2007.11.020

\section{R E F E R E N C E S}

Al-Shahwani, S.M., Horan, N.J., 1991. The use of protozoa to indicate changes in the performance of activated-sludge plants. Water Res. 25, 633-638.

APHA/AWWA/WPCF, 1995. Standard Methods for the Examination of Water and Wastewater, 19th ed. Washington, DC, USA.

Curds, C.R., Cockburn, A., 1970. Protozoa in biological sewagetreatment processes: $(\alpha)$ protozoa as indicators in the activated-sludge process. Water Res. 4, 237-249.

Curds, C.R., 1982. The ecology and role of protozoa in aerobic sewage treatment processes. Annu. Rev. Microbiol. 36, 27-46.

Degans, H., Zöllner, E., Gucht, K.V., Meester, L.D., Jürgens, K., 2002. Rapid Daphnia-mediated changes in microbial community structure: an experimental study. FEMS Microbiol. Ecol. 42, 137-149.

Dighton, J., 1997. Is it possible to develop microbial test systems to evaluate pollution effects on soil nutrient cycling? In: van Straalen, N.M., Lökke, H. (Eds.), Ecological Risk Assessment of Contaminants in Soil. Chapman \& Hall, London, pp. 51-69.

Esteban, G., Téllez, C., Bautista, L.M., 1991. Dynamics of ciliated protozoa communities in activated-sludge process. Water Res. 25, 962-967.

Foissner, W., 1999. Soil protozoa as bioindicators: pros and cons, methods, diversity, representative examples. Agric. Ecosyst. Environ. 74, 95-112.

Forney, L.J., Liu, W.T., Guckert, J.B., Kumagai, Y., Namkung, E., Nishihara, T., Larson, R.J., 2001. Structure of microbial communities in activated sludge: potential implications for 
assessing the biodegradability of chemicals. Ecotoxicol. Environ. Saf. 49, 40-53.

Griffiths, B.S., Ritz, K., Bardgett, R.D., Cook, R., Christensen, S., Ekelund, F., Sörensen, S., Bääth, E., Bloem, J., de Ruiter, P., Dolfing, J., Nicolardot, B., 2000. Ecosystem response of pasture soil communities to fumigation-induced microbial diversity reductions: an examination of the biodiversity-ecosystem function relationship. Oikos 90, 279-294.

Griffiths, B.S., Bonkowski, M., Roy, J., Ritz, K., 2001. Functional stability, substrate utilisation and biological indicators of soils following environmental impacts. Appl. Soil Ecol. 16, 49-61.

Hahn, M.W., Höfle, M.G., 1999. Flagellate predation on a bacterial model community: interplay of size-selective grazing, specific bacterial cell size, and bacterial community composition. Appl. Environ. Microbiol. 65, 4863-4872.

Hahn, M.W., Höfle, M.G., 2001. Grazing of protozoa and its effect on populations of aquatic bacteria. FEMS Microbiol. Ecol. 35, 113-121.

Hansel-Welch, N., Butler, M.G., Carlson, T.J., Hanson, M.A., 2003. Changes in macrophyte community structure in Lake Christina (Minnesota), a large shallow lake, following biomanipulation. Aquat. Bot. 75, 323-337.

Jezbera, J., Horňák, K., Šimek, K., 2005. Food selection by bacterivorous protists: insight from the analysis of the food vacuole content by means of fluorescence in situ hybridization. FEMS Microbiol. Ecol. 52, 351-363.

Jiang, J.G., Wu, S.G., Shen, Y.F., 2007. Effects of seasonal succession and water pollution on the protozoan community structure in an eutrophic lake. Chemosphere 66, 523-532.

Jürgens, K., Pernthaler, J., Schalla, S., Amann, R., 1999. Morphological and compositional changes in a planktonic bacterial community in response to enhanced protozoan grazing. Appl. Environ. Microbiol. 65, 1241-1250.

Kalin, M., Cao, Y., Smith, M., Olaveson, M.M., 2001. Development of the phytoplankton community in a Pit lake in relation to water quality changes. Water Res. 35, 3215-3225.

Lee, S., Basu, S., Tyler, C.W., Wei, I.W., 2004. Ciliate populations as bio-indicators at Deer Island Treatment Plant. Adv. Environ. Res. 8, 371-378.

Liu, X.C., Yang, M., Zhang, Y., Yang, X.P., Gan, Y.P., 2007. Microbial community comparison of different biological processes for treating the same sewage. World J. Microbiol. Biotechnol. 23, 135-143.

Madoni, P., Ghetti, P.F., 1981. The structure of ciliated protozoa communities in biological sewage-treatment plants. Hydrobiologia 83, 207-215.

Madoni, P., Davoli, D., Chierici, E., 1993. Comparative analysis of the activated sludge microfauna in several sewage treatment works. Water Res. 27, 1485-1491.
Madoni, P., 1994. A sludge biotic index (SBI) for the evaluation of the biological performance of activated sludge plant based on the microfauna analysis. Water Res. 28, 67-75.

Martín-Cereceda, M., Serrano, S., Guinea, A., 1996. A comparative study of ciliated protozoa communities in activated-sludge plants. FEMS Microbiol. Ecol. 21, 267-276.

Martín-Cereceda, M., Pérez-Uz, B., Serrano, S., Guinea, A., 2001. Dynamics of protozoan and metazoan communities in a full scale wastewater treatment plant by rotating biological contactors. Microbiol. Res. 156, 225-238.

Nicolau, A., Dias, N., Mota, M., Lima, N., 2001. Trends in the use of protozoa in the assessment of wastewater treatment. Res. Mirobiol. 152, 621-630.

Nicolau, A., Martins, M.J., Mota, M., Lima, N., 2005. Effect of copper in the protistan community of activated sludge. Chemosphere 58, 605-614.

Patterson, D.J., 1996. Free-Living Freshwater Protozoa: A Colour Guide. Manson Publishing Ltd., London.

Pernthaler, J., Posch, T., Šimek, K., Vrba, J., Amann, R., Psenner, R., 1997. Contrasting bacterial strategies to coexist with a flagellate predator in an experimental microbial assemblage. Appl. Environ. Microbiol. 63, 596-601.

Poole, J.E.P., 1984. A study of the relationship between mixed liquor fauna and plant performance for a variety of activated sludge sewage treatment works. Water Res. 18, 281-287.

Salvadó, H., Gracia, M.P., 1993. Determination of organic loading rate of activated sludge plants based on protozoa analysis. Water Res. 27, 891-895.

Salvadó, H., 1994. Effect of mean cellular retention time on ciliated protozoan populations in urban wastement plants based on a proposed model. Water Res. 28, 1315-1321.

Salvadó, H., Gracia, M.P., Amigó, J.M., 1995. Capability of ciliated protozoa as indicators of effluent quality in activated sludge plants. Water Res. 29, 1041-1050.

Shen, Y.F., Zhang, Z., 1990. Modern Biomonitoring Techniques Using Freshwater Microbiota. China Architecture \& Building Press, Beijing.

Šimek, K., Vrba, J., Pernthaler, J., Posch, T., Hartman, P., Nedoma, J., Psenner, R., 1997. Morphological and compositional shifts in an experimental bacterial community influenced by protists with contrasting feeding modes. Appl. Environ. Microbiol. 63, 587-595.

Yoo, C.K., Vanrolleghem, P.A., Lee, I.B., 2003. Nonlinear modeling and adaptive monitoring with fuzzy and multivariate statistical methods in biological wastewater treatment plants. J. Biotechnol. 105, 135-163.

Zarda, B., Mattison, G., Hess, A., Hahn, D., Höhener, P., Zeyer, J., 1998. Analysis of bacterial and protozoan communities in an aquifer contaminated with monoaromatic hydrocarbons. FEMS Microbiol. Ecol. 27, 141-152. 